\title{
RP-HPLC Method Development and Validation for Simultaneous Estimation of Clarithromycin and Paracetamol
}

\author{
Sadana Gangishetty and Surajpal Verma \\ Department of Quality Assurance, School of Pharmaceutical Sciences, Lovely Professional University, Phagwara-Punjab 144411, India \\ Correspondence should be addressed to Surajpal Verma; surajpal_1982@yahoo.co.in
}

Received 11 June 2013; Accepted 21 July 2013

Academic Editors: B. J. Birch, C. M. Chan, R. N. Rao, and B. Rittich

Copyright ( 2013 S. Gangishetty and S. Verma. This is an open access article distributed under the Creative Commons Attribution License, which permits unrestricted use, distribution, and reproduction in any medium, provided the original work is properly cited.

\begin{abstract}
The present work describes a simple, rapid, and reproducible reverse phase high performance liquid chromatography (RP-HPLC) method for the simultaneous estimation of clarithromycin (CLA) and paracetamol (PCM). C18 column (Kromasil ODS, $5 \mu \mathrm{m}, 250$ $\times 4.6 \mathrm{~mm})$ and a mobile phase containing phosphate buffer $(0.05 \mathrm{M})$ along with 1-octane sulphonic acid sodium salt monohydrate $(0.005 \mathrm{M})$ adjusted to $\mathrm{pH} 3.2$ : acetonitrile $(50: 50 \mathrm{v} / \mathrm{v})$ mixture was used for the separation and quantification. The flow rate was $1.0 \mathrm{~mL} / \mathrm{min}$ and the eluents were detected by UV detector at $205 \mathrm{~nm}$. The retention times were found to be 2.21 and $3.73 \mathrm{mins}$, respectively. The developed method was validated according to ICH guidelines Q2 (R1) and found to be linear within the range of $75-175 \mu \mathrm{g} / \mathrm{mL}$ for both drugs. The developed method was applied successfully for assay of clarithromycin and paracetamol in their combined in-house developed dosage forms and in vitro dissolution studies.
\end{abstract}

\section{Introduction}

Clarithromycin is a second generation macrolide with broad spectrum of antibiotic activity. It is active against the organisms which are responsible for bacterial exacerbations of lower respiratory tract infections [1]. Clarithromycin (6$\mathrm{O}$-methyl erythromycin) is synthesized by substituting a methoxy group for the C-6 hydroxyl group of erythromycin. This substitution creates a more acid stable antimicrobial and prevents the degradation of the erythromycin base to the hemiketal intermediate. The increased acid stability of clarithromycin results in improved oral bioavailability and reduced gastrointestinal intolerance [2]. Clarithromycin is characterized by favorable oral bioavailability that achieves $52 \%$ to $60 \%$, whereas its antimicrobial activity involves a concentration and time dependent mode of bacteriostatic action [3]. Clarithromycin is metabolized in the liver and in the stomach. Approximately $22 \%$ of an oral dose is recovered as parent compound, $18 \%$ in the urine and $4 \%$ in the faeces. Clearance of clarithromycin decreases with increasing dose, probably because of saturable hepatic metabolism [4] (see Figure 1).
Paracetamol is a common analgesic and antipyretic drug that is used for the relief of fever, headaches, and other minor aches and pains [5]. Paracetamol is chemically 4hydroxyacetanilide is a centrally and peripherally acting nonopioid analgesic and antipyretic [6]. Paracetamol lacks many of the side effects of aspirin, unlike other common analgesics such as aspirin and ibuprofen, and has no anti-inflammatory properties, and so it is not a member of the class of drugs known as nonsteroidal anti-inflammatory drugs or NSAIDs. Paracetamol does not irritate the lining of the stomach or affect blood coagulation as compared to aspirin. At normal therapeutic doses, paracetamol is metabolized very fast and completely by undergoing glucuronidation and sulphonation to inactive metabolites that are eliminated in the urine $[5,7]$ (see Figure 2).

The present study was designed to develop a simple, precise, and rapid analytical RP-HPLC procedure, which can be used for the analysis of assay method for simultaneous estimation of clarithromycin and paracetamol as there was only individual methods reported for both drugs. The combination of these two drugs is not official in any pharmacopoeia; hence no official method is available for 
TABLE 1: Specificity data.

\begin{tabular}{lccccc}
\hline & Average standard area* $(\mathrm{mV})$ & Avg sample area* $(\mathrm{mV})$ & Standard deviation & RSD\% & Inference \\
\hline CLA & 361.82 & 359.06 & 1.95 & 0.54 & RSD $\%$ found to be $<2$ \\
PCM & 4839.05 & 4824.29 & 10.43 & 0.21 & \\
\hline
\end{tabular}

${ }^{*} n=6$.

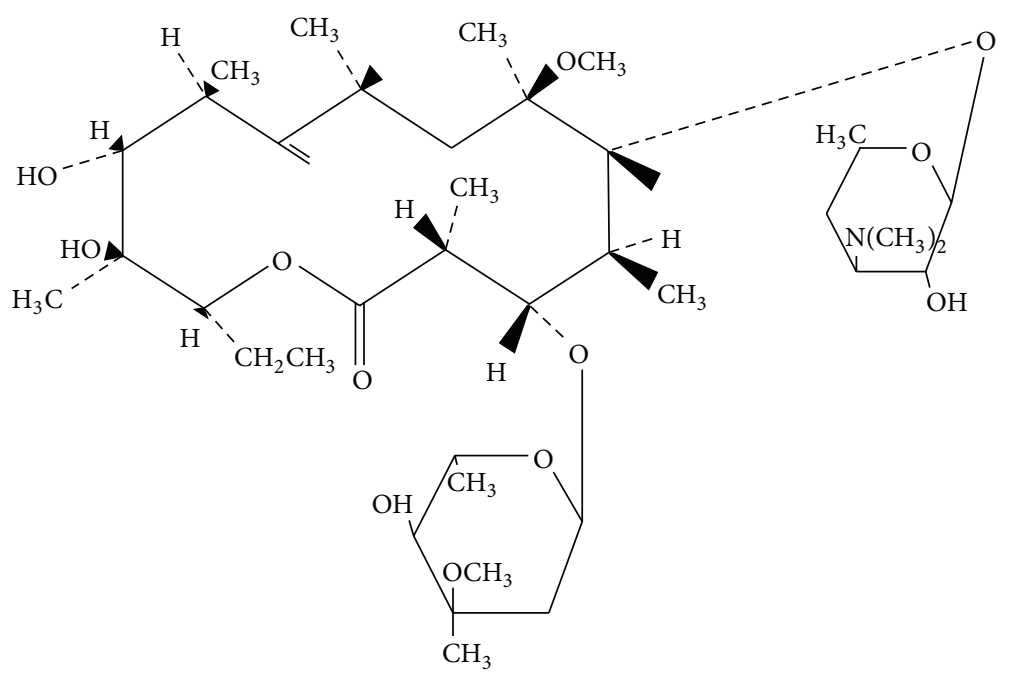

FIGURE 1: Structure of clarithromycin.

TABLE 2: Repeatability and intermediate precision.

\begin{tabular}{cccc}
\hline & CLA & PCM & Inference \\
\hline $\begin{array}{l}\text { Repeatability (RSD\%) } \\
\text { Intermediate precision }\end{array}$ & 1.40 & 0.36 & \\
Analyst 1 (RSD\%) & 0.99 & 0.15 & \% RSD was found to be $<2$ \\
Analyst 2 (RSD\%) & 0.93 & 0.11 & \\
\hline
\end{tabular}<smiles>CC(=O)Nc1ccc(O)cc1</smiles>

FIgURE 2: Structure of paracetamol.

the simultaneous estimation of these two drugs in their combined dosage forms. Literature survey of clarithromycin and paracetamol revealed several methods for detecting these drugs individually but there is no method for their simultaneous estimation using RP-HPLC. These drugs were given as regimen for the treatment of upper respiratory tract infections and tonsillitis.

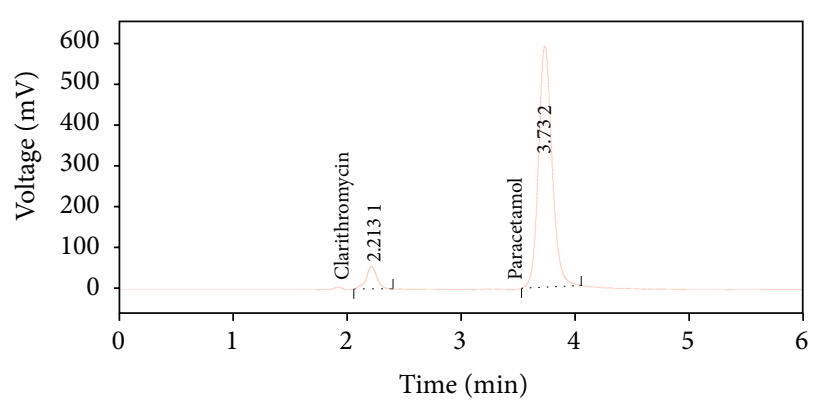

FIGURE 3: Optimized chromatogram of clarithromycin and paracetamol.

The developed method was validated as per ICH guidelines and its updated international convention. The linearity of response, precision, ruggedness and robustness of the described method has been checked.

\section{Experimental}

2.1. Chemicals and Reagents. Clarithromycin standard and API were procured by Jackson Laboratories, Amritsar, India. Paracetamol standard and API were gifted by Shandong yinfied pharmaceutical Co., Ltd., China. Acetonitrile was purchased from Standard Reagents Pvt. Ltd., Hyderabad, India. 1-Octane sulphonic acid sodium salt monohydrate and orthophosphoric acid were purchased from Rankem Ltd., New Delhi, India. All the other reagents used were of analytical grade. 
TABLE 3: Results of LOD and LOQ of clarithromycin and paracetamol.

\begin{tabular}{lccccc}
\hline Method & Range $(\mu \mathrm{g} / \mathrm{mL})$ & Linear regression equation & $R^{2}$ & LOD $(\mu \mathrm{g} / \mathrm{mL})$ & $\mathrm{LOQ}(\mu \mathrm{g} / \mathrm{mL})$ \\
\hline RP-HPLC-CLA & $75-175$ & $2.8086 x+12.432$ & 0.9952 & 5.230 & 15.849 \\
RP-HPLC-PCM & $75-175$ & $33.423 x+80.568$ & 0.9971 & 5.232 & 15.855 \\
\hline
\end{tabular}

TABLE 4: Recovery data for clarithromycin.

\begin{tabular}{|c|c|c|c|c|c|}
\hline $\begin{array}{l}\text { Std conc } \\
(\mu \mathrm{g} / \mathrm{mL})\end{array}$ & $\begin{array}{c}\text { Mean Std area* } \\
(\mathrm{mV})\end{array}$ & $\begin{array}{c}\text { Spl conc (std conc }+ \\
\text { spiked amount }) \\
(\mu \mathrm{g} / \mathrm{mL})\end{array}$ & $\begin{array}{c}\text { Mean Spl area* } \\
(\mathrm{mV})\end{array}$ & $\begin{array}{c}\text { Concentration } \\
\text { obtained }(\mu \mathrm{g} / \mathrm{mL})\end{array}$ & Recovery \% \\
\hline 100 & 303.43 & 106.25 & 326.21 & 107.51 & 101.18 \\
\hline 125 & 365.61 & 131.25 & 387.04 & 132.42 & 100.89 \\
\hline 150 & 425.25 & 156.25 & 447.75 & 157.93 & 101.07 \\
\hline
\end{tabular}

${ }^{*} n=3$.

2.2. HPLC Instrumentation and Conditions. The analysis was carried out on a HPLC system (Shimadzu-LC 20AT) equipped with UV detector, pressure controlled by prominence pump and operated by Spinchrom Software. C18 column $(250 \mathrm{~mm} \times 4.6 \mathrm{~mm}$ i.d., particle size $5 \mu \mathrm{m})$ was used for separation. Mobile phase used for separation was mixture containing monobasic phosphate buffer $(0.05 \mathrm{M})$ along with 1-octane sulphonic acid sodium salt monohydrate (ion-pair reagent) adjusted to $\mathrm{pH} 3.2$ with orthophosphoric acid and acetonitrile $(50: 50 \mathrm{v} / \mathrm{v})$. The flow rate was kept at $1.0 \mathrm{~mL} / \mathrm{min}$, column temperature was ambient $\left(25^{\circ} \mathrm{C}\right)$, eluents were detected by UV detector at $205 \mathrm{~nm}$, and the injection volume was $20 \mu \mathrm{L}$.

2.2.1. Preparation of Phosphate Buffer pH 3.2. The monobasic potassium phosphate was accurately weighed about $6.8 \mathrm{gm}$ and dissolved in distilled water and to this $1.175 \mathrm{gm}$ of 1octane sulphonic acid sodium salt monohydrate was added and dissolved and volume was made up to mark in $1000 \mathrm{~mL}$ volumetric flask.

2.2.2. Preparation of Mobile Phase. Mobile phase was prepared by mixing 50 volumes of acetonitrile and 50 volumes of $0.05 \mathrm{M}$ phosphate buffer along with $0.005 \mathrm{M}$ 1-octane sulphonic acid sodium salt monohydrate and was adjusted to $\mathrm{pH} 3.2$ with orthophosphoric acid. The mobile phase was ultrasonicated, filtered through $0.45 \mu \mathrm{m}$ membrane filter, and degassed.

2.2.3. Preparation of Standard Stock Solution. Standard stock solution was prepared by weighing accurately $125 \mathrm{mg}$ each of clarithromycin and paracetamol individually and dissolved in the $5 \mathrm{~mL}$ of mobile phase in $100 \mathrm{~mL}$ volumetric flask and made up volume with mobile phase. From the above stock solution $5 \mathrm{~mL}$ was taken separately and diluted to $50 \mathrm{~mL}$ to obtain a final concentration $125 \mu \mathrm{g} / \mathrm{mL}$.

2.2.4. Preparation of Working Standard Stock Solution. Working standard stock solution was prepared by weighing accurately $125 \mathrm{mg}$ each of clarithromycin and paracetamol individually and dissolved in $5 \mathrm{~mL}$ of methanol and volume made up with mobile phase in $100 \mathrm{~mL}$ volumetric flask. From the above stock solution $5 \mathrm{~mL}$ was taken separately and diluted to $50 \mathrm{~mL}$ to obtain a final concentration $125 \mu \mathrm{g} / \mathrm{mL}$.

\subsection{Method Validation}

2.3.1. Specificity. Specificity of the method was determined by comparison between standard drug and sample. Fixed concentrations of $125 \mu \mathrm{g} / \mathrm{mL}$ of standard and working test solutions were injected to the HPLC system for six times and were analyzed. Percentage of RSD was calculated from their peak areas.

\subsubsection{Precision}

Repeatability. Precision of the method was studied by making repeated injections of the mixture of drugs on the same day for intraday precision. The coefficient of variation (CV) after five determinations was determined at $125 \mu \mathrm{g} / \mathrm{mL}$ for both drugs.

Intermediate Precision. Intermediate precision was carried out by injecting three replicates of standard concentration $(125 \mu \mathrm{g} / \mathrm{mL})$ by different analysts. The $\%$ RSD was calculated.

2.3.3. Linearity. The linearity of measurement was evaluated by analyzing standard solutions of CLA and PCM in the range of $75-175 \mu \mathrm{g} / \mathrm{mL}$ for both drugs and calibration plot was constructed.

2.3.4. Limit of Detection (LOD) and Limit of Quantitation (LOQ). LOD and LOQ of CLA and PCM were determined by calibration curve method. Solutions of clarithromycin and paracetamol were prepared in the range of $75-175 \mu \mathrm{g} / \mathrm{mL}$ and injected in triplicate.

2.3.5. Accuracy. Accuracy of the method was calculated by recovery studies at three levels by standard addition method, that is, spiking about $6.5 \mu \mathrm{g} / \mathrm{mL}$ of each of CLA and PCM to the standard solutions containing 100,125 , and $150 \mu \mathrm{g} / \mathrm{mL}$. 
TABLE 5: Recovery data for paracetamol.

\begin{tabular}{|c|c|c|c|c|c|}
\hline $\begin{array}{l}\text { Std. } \\
\text { concentration } \\
(\mu \mathrm{g} / \mathrm{mL})\end{array}$ & $\begin{array}{c}\text { Mean Std area* } \\
(\mathrm{mV})\end{array}$ & $\begin{array}{l}\text { Spl. concentration } \\
\text { (std conc }+ \text { spiked } \\
\text { amount })(\mu \mathrm{g} / \mathrm{mL})\end{array}$ & $\begin{array}{c}\text { Mean Spl area* } \\
(\mathrm{mV})\end{array}$ & $\begin{array}{c}\text { Concentration } \\
\text { obtained }(\mu \mathrm{g} / \mathrm{mL})\end{array}$ & Recovery \% \\
\hline 100 & 3776.59 & 106.25 & 3966.03 & 107.51 & 98.84 \\
\hline 125 & 4802.27 & 131.25 & 5093.54 & 132.58 & 101.01 \\
\hline 150 & 5416.54 & 156.25 & 5704.80 & 157.98 & 101.11 \\
\hline
\end{tabular}

${ }^{*} n=3$.

Linearity of clarithromycin (CLA)

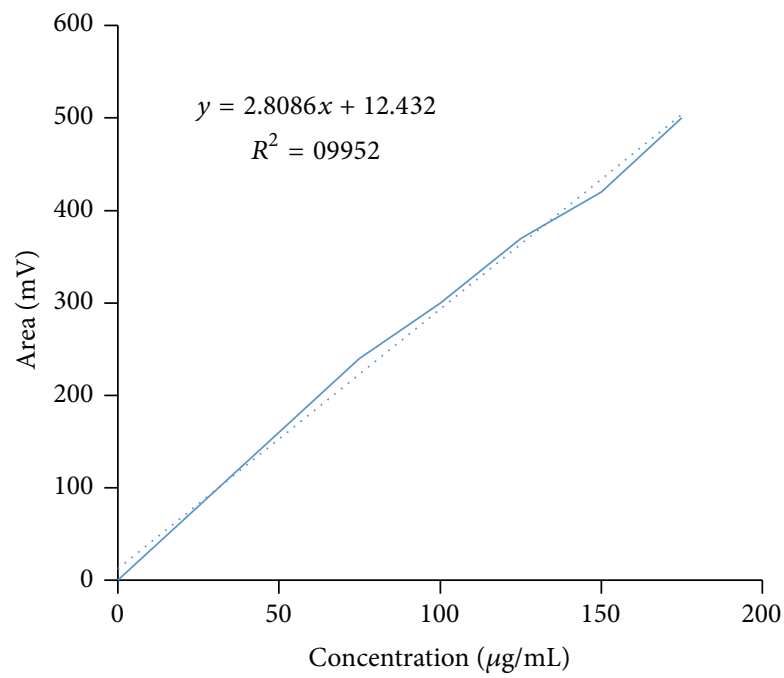

(a)
Linearity of paracetamol (PCM)

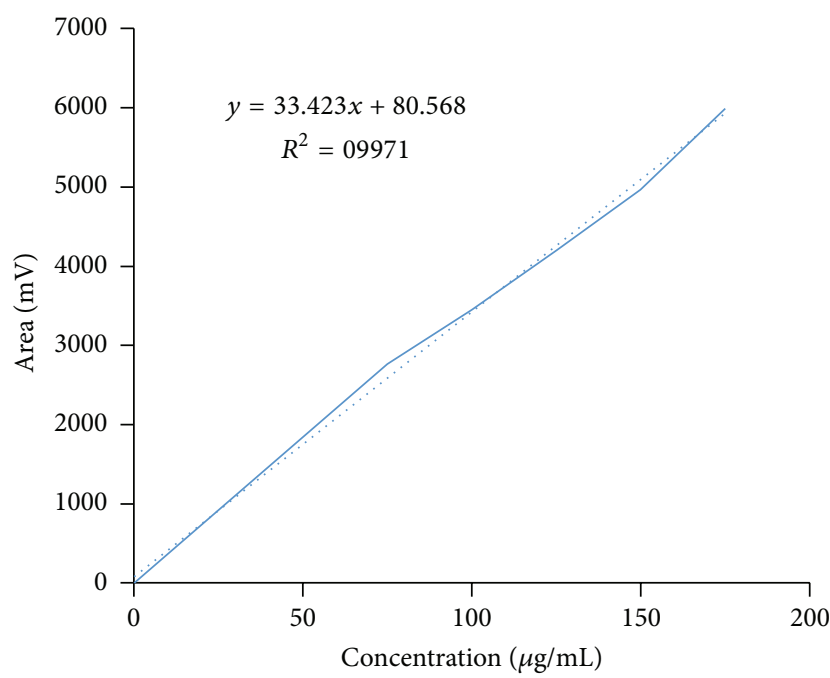

(b)

FIGURE 4: Linearity plot of CLA (a) and PCM (b) $(75-175 \mu \mathrm{g} / \mathrm{mL})$ standard solution.

TABLE 6: Results of robustness.

\begin{tabular}{lccl}
\hline Parameter & $\begin{array}{c}\text { CLA } \\
(\% \\
\text { RSD })\end{array}$ & $\begin{array}{c}\text { PCM } \\
(\% \\
\text { RSD })\end{array}$ & Inference \\
\hline $\begin{array}{l}\text { Flow rate }( \pm 0.2 \mathrm{~mL} / \mathrm{min}) \\
\quad \\
\quad 0.8 \mathrm{~mL} / \mathrm{min}\end{array}$ & 0.31 & 0.12 & RSD \% was \\
$\quad 1.2 \mathrm{~mL} / \mathrm{min}$ & 0.59 & 0.25 & found to be $<2$ \\
Wavelength $( \pm 2 \mathrm{~nm})$ & & & \\
$\quad 203 \mathrm{~nm}$ & 0.42 & 0.23 & \\
$207 \mathrm{~nm}$ & 0.30 & 0.25 & \\
\hline
\end{tabular}

TABLE 7: System suitability parameters.

\begin{tabular}{lcc}
\hline \multirow{2}{*}{ Parameters } & \multicolumn{2}{c}{ Proposed method } \\
& PCM & CLA \\
\hline Retention times & 2.21 & 3.73 \\
Theoretical plates & 29044 & 48040 \\
Tailing factor & 0.833 & 1.242 \\
Resolution & & 7.992 \\
\hline
\end{tabular}

The samples were injected in triplicate and their \% recovery was determined.
2.3.6. Robustness. Influence of small changes in chromatographic conditions such as change in flow rate, that is, $\pm 0.2 \mathrm{~mL} / \mathrm{mins}$ and wavelength of detection $\pm 2 \mathrm{~nm}$, was studied to determine the robustness of the method for the development of RP-HPLC method for the simultaneous estimation of CLA and PCM and their \%RSD was determined.

2.3.7. System Suitability. The stock solution containing $125 \mu \mathrm{g} / \mathrm{mL}$ was injected and repeated five times and the chromatograms were recorded. The resolution, number of theoretical plates, and peak asymmetry were calculated to determine whether the result complies with the recommended limit.

\section{Results and Discussion}

3.1. Optimization of Chromatographic Conditions. To develop suitable RP-HPLC method for simultaneous estimation of clarithromycin and paracetamol, different chromatographic conditions were applied and optimized chromatographic conditions were developed (see Figure 3).

Optimized chromatographic conditions are as follows:

instrument: HPLC Shimadzu separation module LC20AT Prominence liquid chromatograph, 
mobile phase: acetonitrile: phosphate buffer along with 1-octane sulphonic acid sodium monohydrate $\mathrm{pH} 3.2(50: 50 \mathrm{v} / \mathrm{v})$,

column: Kromasil C18 $(250 \mathrm{~mm} \times 4.6 \mathrm{~mm}, 5 \mu \mathrm{m})$,

injection volume: $20 \mu \mathrm{L}$,

flow rate: $1.0 \mathrm{~mL} / \mathrm{min}$,

detection wavelength: $205 \mathrm{~nm}$,

run time: $8 \mathrm{~min}$,

temperature: Ambient $\left(25^{\circ} \mathrm{C}\right)$.

\subsection{Validation}

\subsubsection{Specificity. (See Table 1).}

3.2.2. Precision and Intermediate Precision. Precision of the method was studied by making repeated injections of the mixture of drugs. The Coefficient of variation (CV) after five determinations was $1.4 \%$ at $125 \mu \mathrm{g} / \mathrm{mL}$ for CLA and $0.36 \%$ at $125 \mu \mathrm{g} / \mathrm{mL}$ for PCM (see Table 2).

3.2.3. Linearity. The linearity of an analytical procedure is its ability (within a given range) to obtain test results which are directly proportional to the concentration (amount) of analyte in the sample. LOD and LOQ of CLA and PCM were determined by calibration curve method. Solutions of clarithromycin and paracetamol were prepared in the range of $75-175 \mu \mathrm{g} / \mathrm{mL}$ and injected in triplicate (see Figure 4).

3.2.4. Limit of Detection (LOD) and Limit of Quantitation (LOQ). LOD and LOQ of clarithromycin and paracetamol were determined by calibration curve method. Solutions of clarithromycin and paracetamol were prepared in the range of $75-175 \mu \mathrm{g} / \mathrm{mL}$ and injected in triplicate (see Table 3 ).

3.2.5. Accuracy. Accuracy of the method was calculated by recovery studies at three levels by standard addition method. The mean percentage recoveries obtained for clarithromycin and paracetamol were $101.04 \%$ and $99.76 \%$, respectively (see Tables 4 and 5).

3.2.6. Robustness. The method for the development of RPHPLC method for the simultaneous estimation of CLA and PCM was found to be robust as the $\%$ RSD was found to be less than 2 (see Table 6).

3.2.7. System Suitability. The resolution, number of theoretical plates, and peak asymmetry were calculated for the standard solutions. The stock solution containing $125 \mu \mathrm{g} / \mathrm{mL}$ was injected and repeated five times and the chromatograms were recorded. The resolution, number of theoretical plates, and peak asymmetry were calculated to determine whether the result complies with the recommended limit (see Table 7).

\section{Conclusion}

The proposed RP-HPLC method was used for the simultaneous estimation of clarithromycin and paracetamol was found to be sensitive, accurate, precise, simple, and rapid. Hence the present RP-HPLC method may be used for routine analysis of the raw materials, in vitro dissolution study of combinational dosage formulations containing clarithromycin and paracetamol.

\section{Conflict of Interests}

The authors do not have a direct financial relation with the commercial identity mentioned in paper that might lead to a conflict of interests for any of the authors.

\section{References}

[1] D. Adam, E. Glaser-Caldow, J. Wachter et al., "Comparative efficacy of clarithromycin modified-release and clarithromycin immediate-release formulations in the treatment of lower respiratory tract infection," Clinical Therapeutics, vol. 23, no. 4, pp. 585-595, 2001.

[2] J. M. Zuckerman, "Macrolides and ketolides: azithromycin, clarithromycin, telithromycin," Infectious Disease Clinics of North America, vol. 18, no. 3, pp. 621-649, 2004.

[3] A. Giannopoulos, G. Koratzanis, E. J. Giamarellos-Bourboulis, C. Panou, I. Adamakis, and H. Giamarellou, "Pharmacokinetics of clarithromycin in the prostate: implications for the treatment of chronic abacterial prostatitis," Journal of Urology, vol. 165, no. 1, pp. 97-99, 2001.

[4] P. G. Davey, "The pharmacokinetics of clarithromycin and its 14-OH metabolite," Journal of Hospital Infection, vol. 19, pp. 2937, 1991.

[5] M. E. Bosch, A. J. R. Sánchez, F. S. Rojas, and C. B. Ojeda, "Determination of paracetamol: historical evolution," Journal of Pharmaceutical and Biomedical Analysis, vol. 42, no. 3, pp. 291321, 2006.

[6] M. Khanmohammadi, M. Soleimani, F. Morovvat, A. B. Garmarudi, M. Khalafbeigi, and K. Ghasemi, "Simultaneous determination of paracetamol and codeine phosphate in tablets by TGA and chemometrics," Thermochimica Acta, vol. 530, pp. 128-132, 2012.

[7] Y. Ozkan, A. Savaser, Y. Ozalp, and A. Isimer, "Dissolution properties of different designed and formulated salbutamol tablet dosage forms," Acta Poloniae Pharmaceutica, vol. 57, no. 4, pp. 33-41, 2000. 

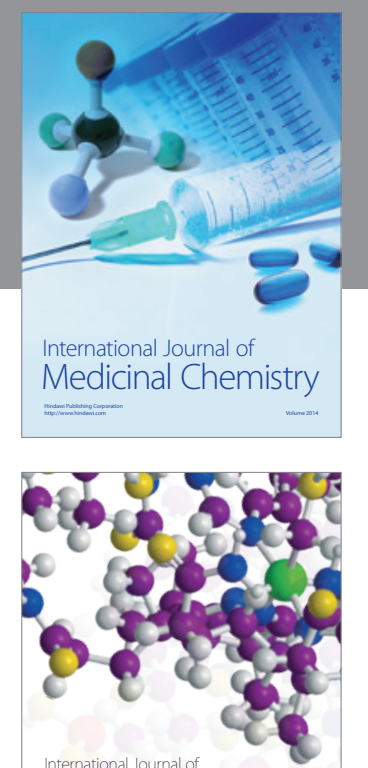

\section{Carbohydrate} Chemistry

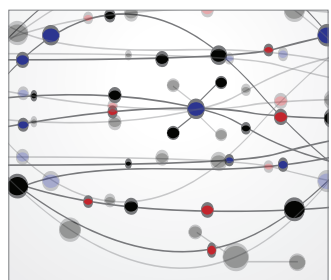

The Scientific World Journal
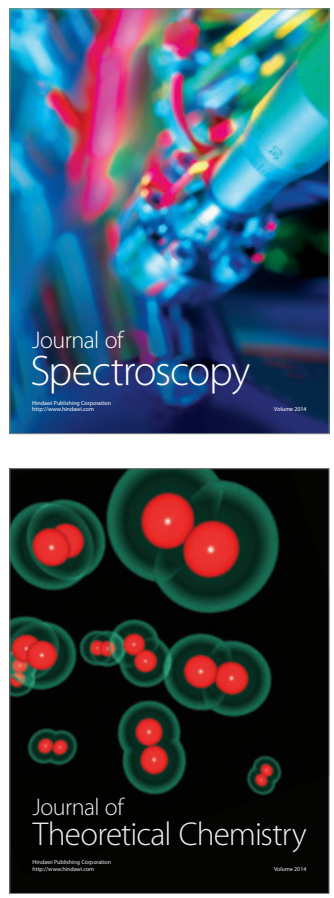
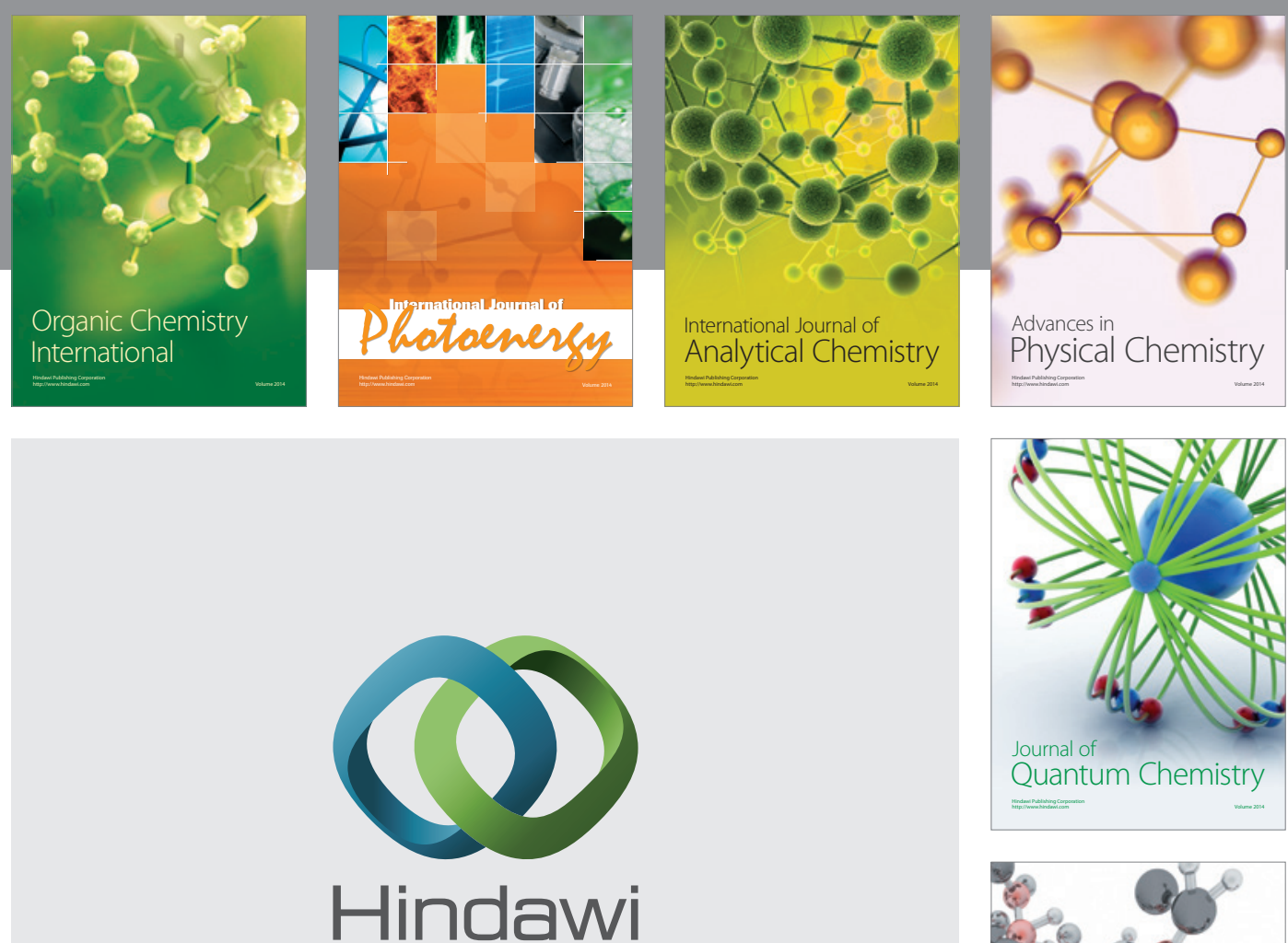

Submit your manuscripts at

http://www.hindawi.com

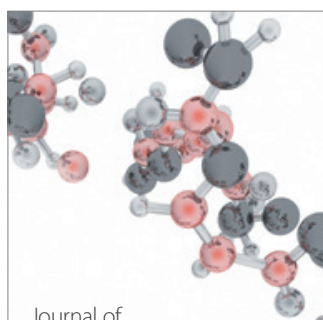

Analytical Methods

in Chemistry

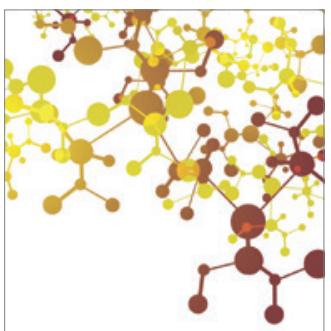

Journal of

Applied Chemistry

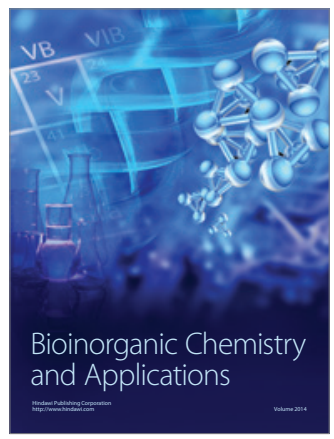

Inorganic Chemistry
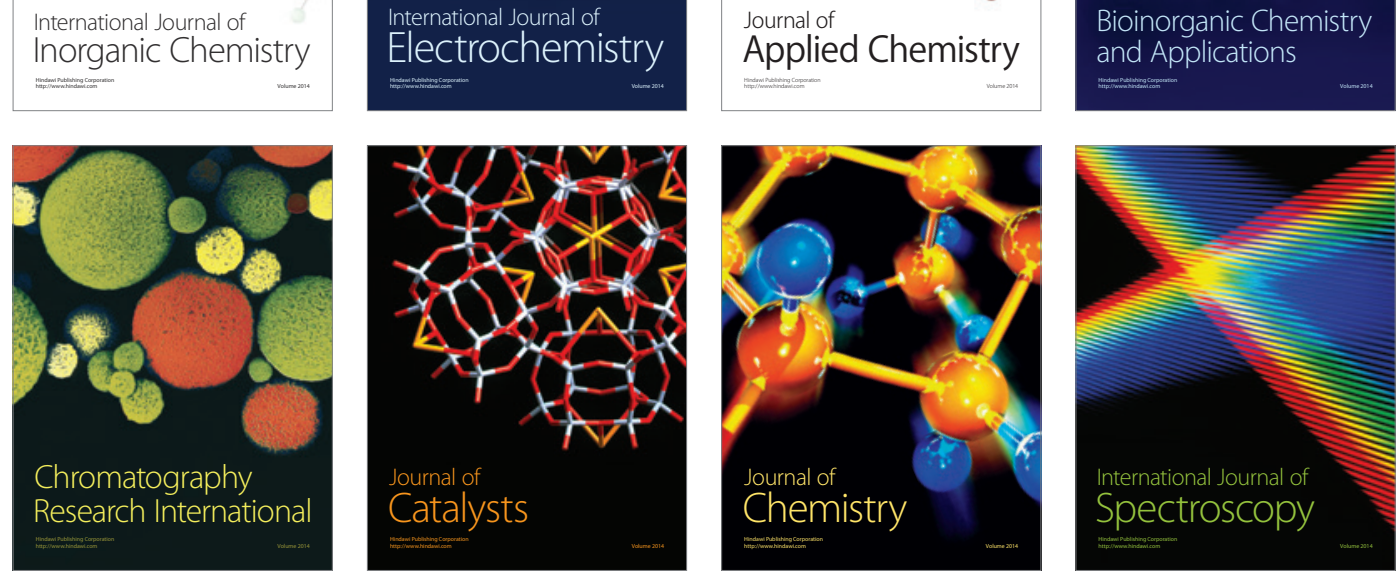